\title{
Friederike Wapler
}

\section{Kinderrechte und Kindeswohl}

\section{Eine Untersuchung zum Status des Kindes im Öffentlichen Recht}

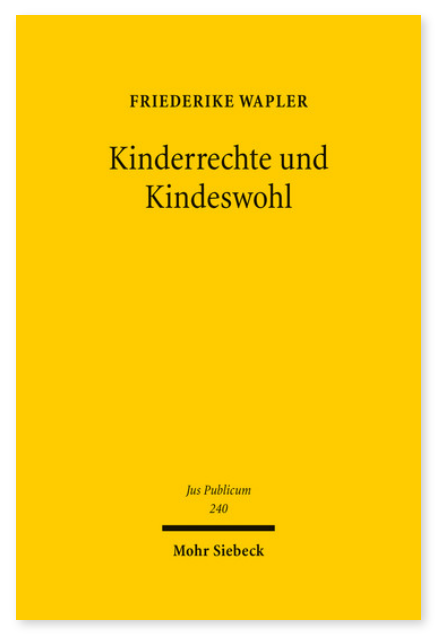

2015. XXIV, 631 Seiten. JusPubl 240

ISBN 978-3-16-153376-1

DOI 10.1628/978-3-16-153376-1

eBook PDF 149,00€

ISBN 978-3-16-153375-4

Leinen $149,00 €$
Die Kinderrechtskonvention der Vereinten Nationen enthält umfassende Menschenrechtsgarantien für Minderjährige und verlangt, bei Entscheidungen über Belange des Kindes dessen Wohl vorrangig zu berücksichtigen. Auch im Verfassungsrecht ist das Kind als Träger von Grund- und Menschenrechten anerkannt. Im Detail ist jedoch vieles unklar: Kann das Kind seine Rechte selbst wahrnehmen oder müssen Dritte dies zu seinen Gunsten tun? Erlangt es aus einem Recht eine autonome Entscheidungsmacht oder ist »ein Recht zu haben« für das Kind gleichbedeutend mit einem Anspruch auf Schutz und Hilfe durch andere?

Friederike Wapler geht diesen Fragen aus öffentlich-rechtlicher wie rechtsphilosophischer Perspektive nach. Im Mittelpunkt steht eine Theorie der dynamischen Entwicklung der kindlichen Selbstbestimmungsfähigkeit, die dem Kind einen Anspruch verleiht, an der Entscheidung über seine eigenen Angelegenheiten in jedem Lebensalter angemessen beteiligt und in seinen individuellen Belangen berücksichtigt zu werden.

Friederike Wapler ist Professorin für Rechtsphilosophie und Öffentliches Recht an der Johannes Gutenberg-Universität Mainz.

Jetzt bestellen:

https://mohrsiebeck.com/buch/kinderrechte-und-kindeswohl-9783161533761?no_cache=1

order@mohrsiebeck.com

Telefon: +49 (0)7071-923-17

Telefax: +49 (0)7071-51104 